\section{Behind and beyond surgery}

\author{
Part I: A world for happy times
}

\section{F. M. Riegler}

Published online: 15 March 2017

(C) Springer-Verlag Wien 2017

\section{Dear reader,}

Welcome to this issue of European Surgery, including a colorful rainbow of novel and highly motivating innovations in surgery. The well-known Viennese surgeon Rene H. Fortelny orchestrates a beautiful spectrum of papers on the fascinating topic of modern, minimally invasive hernia surgery. Thus I refer to his Editorial leading the brilliant firework of surgical science [1]. In summarizing the topics of the 39th Annual International Congress of the European Hernia Society, held 24-27 May 2017, in Vienna, Austria - congress president: Rene H. Fortelny, I hope to motivate you to attend the high-quality international scientific meeting [2-6]. Finally, articles in this issue of European Surgery describe novelties regarding esophagogastric (gastric tube formation) [7], colorectal (mortality after emergency surgery) [8], and minimally invasive surgery (two-trocar appendectomy) [9]. May the publications contribute toward enriching your knowledge and surgical skills.

In recent years, the editorials (Latin: ex edere $=$ offer, reveal, bring into existence) in the issues of European Surgery aimed to shed light on the essence behind and beyond medicine and surgery. A disease does not only represent a condition for diagnosis, treatment, and follow-up. There exists something else! This (part I) and the upcoming editorial (part II) sum up and finalize this attempt, which has now come to an end. Time will tell whether the attempt will find acceptance and may contribute to foster and stimulate happy, positive reasoning for the future of medicine. May humility and gratitude replace greed, envy, and hate. The author questions the basis for happiness, suc-

\section{F. M. Riegler ( $₫)$}

Reflux Medical, Mariannengassse 10/9, 1090 Vienna, Austria martin.riegler@refluxmedical.com cess, wealth, perception, and reasoning (part I) and the common ground for all diseases (part II). Part I and II mirror the soil of the garden for the flowers of our future. The future listens to the silent care of the flowers and their "bliss upon bliss." And here we enter part I.

Cogito sum (not: cogito ergo sum) and, love is beautiful. You never can give and get too much of it. Believe in yourself. Create your own opinion. Never stop to ask questions! Do not copy others. Keep your identity! Be open-minded! Be open for new ideas, approaches, and therapies. Life is unique, great, wonderful, sunny, and full of possibilities, colors, and happy streams. Beautiful is what you sense. Amazing is that you sense. Sadness means: you do not know how to decide. Trust in yourself! Whatever you do, do it with love in your eyes, with a smile on your face. Botox injections harbor a mask, not a smile. By contrast, a smile makes you look beautiful. With an honest smile on your face you will be accepted, people will want to communicate with you, and consequently you will foster success. Beware of being misused, controlled, and misguided for and by any form of despotism. During your conduct of reasoning, critically test and re-evaluate the sayings and the knowledge of your so-called teachers and what has been stated to be the truth. Watch out: Never trust your teachers, they may be brainwashed by invisible despotism.

If you are a leader, avoid despotism and foster the open-minded conduct of reasoning. Allow for novelties for you and others. Do not isolate yourself! Do not stop communicating with others! do not hide behind books, computers, and arguments! You cannot escape the world, because the world makes up your existence! You are diluted within your world. In your life, everything is about you and your existence. As long as you are, others come and go. Do not please! Never forget to know: you came to be finite! Treat your employees 
with fairness, respect and motivate them to be better than you. If you are an employee, respect leaders and colleagues for fair cooperation. Balance and passion foster wealth, success, and happiness. This approach will increase your productivity within competition and development. The basis for success allows for the natural authority of knowledge and the openminded inter- and multidisciplinary management of states of affairs (diseases, relations, legacies). Both, leaders and employees: foster responsibility and forgive mistakes. All colors have the potential to rise. All drops are equally important to mirror the rain(bow), the cloud, the dust, the well, the river, the pond, and the sea. Avoid superficiality, it creates enemies and inhibits you from reaching the essence. Without sensing the essence, all your actions fail to contribute positively to life and thought. Zodiacs teach: yes, we cancer.

\section{How to think positive}

You are a surgeon, pathologist, internist, physiologist, radiologist, ENT specialist. If you dislike a condition, state of affairs, aspect of your life, either at your job or in your private life, go ahead and accurately characterize, assess, define, and treat it: Do not resist accepting help and professional support from others. Otherwise you will bring dark clouds into your sky and shade into your heart. You cannot be successful when you emit negative vibrations. Think positive, there is no need to think negative. It all happens in your head, in your brain, your world is brought into existence within and during your reasoning. You are the center of your world and you can do a lot to keep it shining positively. Let your judgment shine! Let your opinion smile! Let your reasoning be! And now we will summarize the basics of perception (= surgery, symptoms, and signs).

\section{Reality, possibility, nothing}

Surgery always happens as perception and translates symptoms and signs into therapies and prognosis. Surgical science collects (Greek= legein: collect; logos: show, what you collect in the form of words) perceptions for understanding and knowledge, which in turn serve to calculate and justify medical management algorithms. Essentially, perception happens individually and runs within and during a continuous stream of mood, atmosphere, gloom, tune, temper, and emotion (how you feel).

Perception tunes awareness, which is going around in $m y$ brain. Basically, one cannot tell what is going on in the brain of another individual. A multifunctional CT scan or MRI scan of the brain demonstrates where energy uptake (glucose uptake) is increased, but this image does not demonstrate what an individual essentially thinks, feels, and is, except the fact that the person may be sick, suffering the consequences of a stroke or tumor etc. However, it is important to consider what an individual thinks, because what an individual thinks defines and makes up her or his existence! The essence of existence translates into being. There are forms and manifestations of being that we are allowed to know, i. e., reality, those that are speculative (possibilities), and those we are not aware of, i. e., "nothing" or "not to be." About the latter we cannot even speculate, suggest, or assume. Nothing is for sure, except: what is going around in my brain. Reasoning defines being and works with models, ideas, and theories: how I think that the world "happens" during my existence and how the world could be, i. e., "cogito sum" or "cogito ergo sum." Perceptions appear as inner and outer world stimuli. Knowledge represents the interpretation of stimuli-generated emotion and is perceived as "my life" along time within space. During perception, being tunes emotional mood and orchestrates our existence.

\section{Physics}

Surgery is based on physics. Physics aims to assess, catalogue, define, and explain all possible observations of the world. Physics models, describes, analyzes, and treats phenomena along the regular pulsatile offerings of time within a (curved) space. In addition, physics tries to explain the basic mechanisms for change, development, force, speed, motion, power, and light. Based on knowledge, physics develops technologies that allow us to improve and ease the management of the world, i. e., machines, devices, instruments, and compounds for diagnosis and therapy (medical, surgical, oncological disease management). Most importantly, the theory of relativity calculates the physical characteristics of objects (Latin: objectum = thrown against) and energies (light) along the arbitrary mathematical functions of time and space (Fig. 2). But the assessment of these relations does not reveal anything regarding the relation of these objects to being. Physics does not ask: What is the background against which perceptions are made? This may be essential, since the analysis of this question will show and edit an exciting revelation: It is all about you (Fig. 1)!

An object may have qualities, an object may be green, red, blue; it may be hard, soft, solid, liquid; it may be sweet, spicy, bitter; dry, bleeding, wet; large, small; open, closed etc.; thus an object may be of particular substance, quality, and matter. Substance, quality, and matter are brought into our perception with or without the presence or absence of amplifiers (optical, acoustical, sensory; laparoscopy, endoscopy, electrocardiogram, ultrasound). Amplifiers are the children of physics, there would be no amplifiers without physics. Physics fosters smiles. Physics measures, quantifies, and objectifies the qualities and thus makes them open for statistical calculation and representation. In addition we have to ask: What 


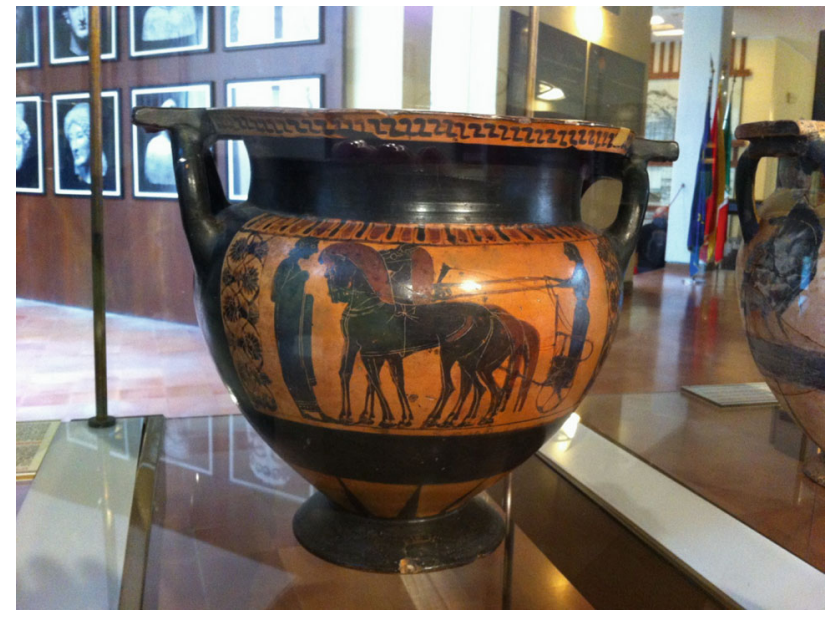

Fig. 1 Ancient Greek vase (around 550 B.C.) portraying an image that was described in the opening scene of the didactic poem by Parmenides (app. 520-460 B.C.): The carriage drawn by four horses brings the scholar to the goddess aletheia (truth). The image remembers the legend of an old cosmic knowledge (truth): The four horses stand for the four movements of the earth against the stellar background, i. e., around its own axis (day/ night), around the sun (years), around the axis of precession (great year of the zodiacs; 26,000 years, app. 2600 years per zodiac), and the tilt of the earth axis (producing the seasons). Thus the vase relates to the relationship of human existence to being, as outlined in the text. Optical biopsy obtained in January 2017, at the Archeological Museum of Agrigento, Sicily, Italy

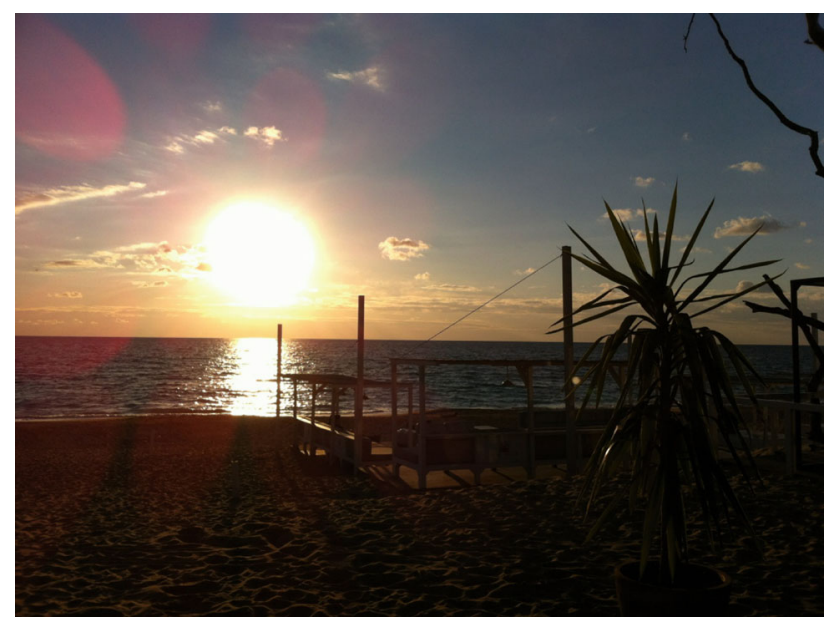

Fig. 2 Since ancient times, human iconography registers the sun as the cosmic sign for duration (time) and extension (space) including the modern concept of relativity. The image mirrors the idea of the author, that existence "shines" during positive reasoning against the background of our state of mood, atmosphere, and emotion. Optical biopsy obtained during sunset, January 2017, on a beach south of Agrigento, Sicily, Italy

defines the relation of perceptions to their being? What makes them come into existence? Is there an existence other than ours? What defines their being? Are these questions addressable by the methods (i. e., ways) of physics, anatomy, physiology, pathology, surgery, oncology, translational medicine, genetics?
What happens beyond calculation? What happens during calculation?

Life reveals a continuous film (note: this statement is not sponsored by the Hollywood film industry). Perception of objects (endoscopy, laparoscopy; liver, gut, blood, heart; tumor, polyp, ulcer, bleeding; colleague, patient, husband, wife, friend, enemy, competitor) happens in the brain (in the form of a continuous film) and creates the being of these objects. Perception happens against the background of your mood, atmosphere, and emotion. Therefore, the state of mood of the person who makes the perception is crucial for the being and decides on the interpretation ("knowledge") of an object.

Let us go for a model that mirrors the essential relation between perception and being: If a person dies, it is not the person who goes away, but the being of the person changes, something seems to alter, vanish, escape, lack; something is different and is out of existence, something does indeed stop being and seems to somehow leave "my world." And this "something" is very strong and powerful, since it represents the most effective and essential promoter for the expression of the human being: art, culture, politics, and science. This something even drove the development of all technologies used for peace (Woodstock festival; minimally invasive and molecular surgery, public transportation, computer etc.) and warfare (tanks, bombs, guns). Economy will teach us why the being of both sides of the coin is best met in Wall Street. It remains to be asked: What makes the being of an object (liver, colon, stomach, lung, thyroid, pancreas, kidney, aorta, blood, nerve; cell; cell membrane; nucleus; tight junction; protein receptor; tyrosine kinase; atom; electron)? Your state of mood, your atmosphere decides on the being of an object. Why would it be important to know about the emotions of an individual during the perception of a particular object: blood coming out of a vessel; assessment of the passion-negative face $(\mathrm{P}-)$ of a competition-positive colleague $(\mathrm{C}+)$ ? Because the state of mood and atmosphere decides on the reactions induced by the perception (clip the vessel; leave the room; increase of blood pressure). Finally, one question cannot be answered for sure: Can there be a world without you or us?

\section{Beyond physics}

Operated within humanistic boundaries, physics fruitfully helps us to understand, support, and develop human qualities (humility, thankfulness; greed, hate,) and to improve the life quality and productivity of man (technologies, medicine, oncology). Within the other range of the spectrum, physics serves to help man increase political, economic, and military power (warfare). Basically metaphysics is physics and contains physics and thus represents a special form of physics. Metaphysics aims to explain and justify human conduct of reasoning (why we do this and that). 


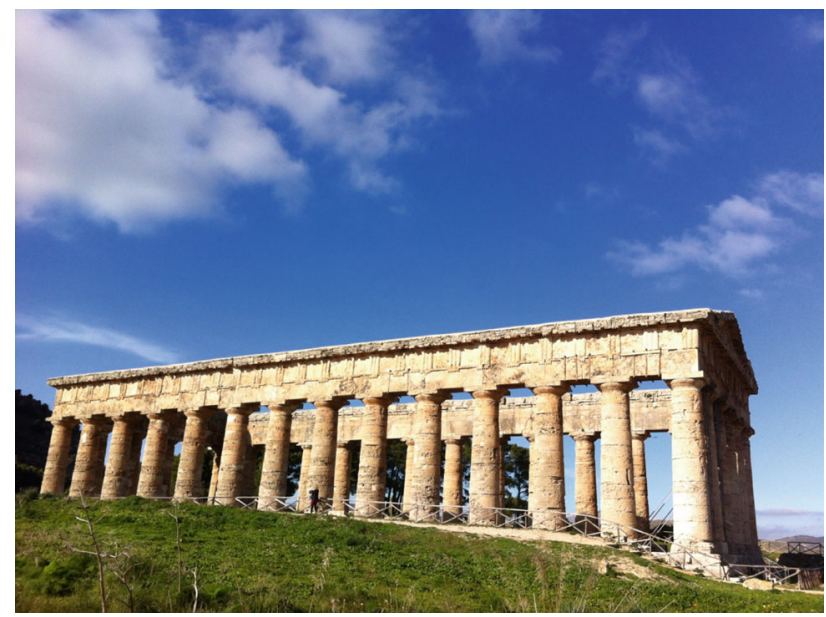

Fig. 3 The unfinished ancient Greek temple of Segesta (420 B.C.) pleases because it mirrors the perfect balance and harmony between praxis and theory. This balance is of majorimportance for successful surgery, as outlined in the text. Optical biopsy obtained in Segesta, January 2017, at the Archeological Museum of Agrigento, Sicily, Italy

At its very essence, metaphysical reasoning serves to justify the increase of will for more power and possession. Thus metaphysics also contains the arguments to justify the global misuse of power (physics). Therefore, metaphysics serves to justify physics, i. e., will for more power, will to increase power.

The world is full of energy and consists of perceivable (reality, possibility) and imperceptible things ("nothing"). The latter should not be named nothing, the imperceptible things simply cannot be perceived by us because we lack the respective senses, thoughts, and/or translators that bring them to our attention, i. e., we lack the machines to visualize, hear, feel, measure them. Black, invisible holes in the sky may be the origin of the future. Being reveals itself as truth. Truth is what is going on in your brain. You are permanently walking and living within your truth. The term fantasy simply denotes another form of truth. Thus there exists no general and universal truth. Truth is accessed individually. Either things are perceivable to you or not. One cannot know everything, but everything knows you. One cannot perceive and sense everything, but everything senses and perceives you. "Nothing" does not exist, the term "nothing" simply implies that you are not able to perceive it, sense it. Everything interacts with each other. The proof is held within the theory of curved space, where the gravity of invisible objects deviates the streams and beams of light. As such we only can speculate whether the indirect recent evidence of the discovery of new planets allows us to suggest they fit within a life-positive/ compatible horizon.

Aristotle knew about physics, ethics, and logic. In our modern world this translates into the forms of technology, economy (money), and semiotics (operation with signs). All three "disciplines" and meta- physics serve to justify the stabilization and increase of "power." As a crucial matter of fact, money calculates modern ethics. Today money-driven extremes (global market; will for more consumption) define the qualities of life and productivity. "Excel experience" teaches us what serves to improve life and thus is included into the daily routine of life. Selection serves to define the useful (good) and the bad (money loss). Modern life seems to run against our nature! We get sick, lonely, and devaluated. Man faces an exodus into the slavery of modern ethics. Metaphysics powers the fuel for the global venture. After that, robots will come into power and use us to farm their world. Change sheds new light on the case. Hopefully this episode will help to take us back to our roots and fruitfully fulfill the legacy of our existence: How can we learn to think essential?

\section{Sunny balance between theory and praxis}

Surgery happens within the spectrum of life and death. Humans always search for harmony (Fig. 3). Essentially all human actions (physics, medicine, art) and metaphysics (its justification; philosophy) serve two extremes of reasoning: They aim to direct our attention away from the awareness of our finiteness (existence), and to direct our reasoning toward our existence (being). Thus man lives in episodes where he/she is directed away (praxis) and/or toward "being" (theory). Only few individuals are aware of how to live in a balance between praxis and theory: away from and toward their being (Fig. 2 and 3). It seems that we are not allowed to know anything about our individual death during life; perhaps all becomes clear during the short moments before and during this important event. There are two moments of our life that we do not remember: birth and death. The "gap" of memory is sensed - but not perceived - as energy, arising within the dimensions of the intraphysical horizon (orion!) of our perceptions (Fig. 1).

In the next issue of European Surgery, Part II of the considerations will finalize the attempt of the author and deal with a novel understanding of the pathogenesis of disease, and how this understanding translates into basic science, diagnosis, and therapies.

Enjoy spring 2017, stay tuned, harbor your day, and allow yourself to ask: "What is now?"

Acknowledgements The author thanks being and you for reading these lines. He thanks his family, friends, teachers, and colleagues for their understanding, passion, and support. Most importantly, the author thanks his patients: Their histories profoundly contributed to an alternative understanding of disease (being sick), as outlined in the editorials. The author thanks the support and contributions of the coeditors, reviewers, authors, the editorial board members of European Surgery, and the members of the surgical and medical societies, for whom European Surgery is allowed to serve as the official publication platform. Without their activities, European Surgery would not exist! Finally, the author 
thanks Springer Vienna and the great support offered by the members of the editorial office (Julia, Gabriele, Alois).

Conflict of interest F. M. Riegler declares that he has no competing interests.

\section{References}

1. Fortelny RH. Editorial. Eur Surg. 2017. doi:10.1007/s10353017-0468-y.

2. Petter-Puchner AH, Gruber-Blum S, Redl $\mathrm{H}$ et al. Mesh technologies and challenges in modern hernia surgery and abdominal wall repair. Eur Surg. 2017. doi:10.1007/s10353017-0470-4.

3. Reinpold W, Schröder M, Schröder A et al. Minimally Invasive Sublay Mesh Repair of Incisional and Primary Abdominal Wall Hernias using the MILOS technique. Eur Surg. 2017. doi:10.1007/s10353-017-0475-z.

4. Bittner R, Schwarz J. Endoscopic Mini/Less Open Sublay (EMILOS) operation in the treatment of primary and sec- ondary ventral hernias of the abdominal wall. Eur Surg. 2017. doi:10.1007/s10353-017-0472-2.

5. Köckerling F, Botsinis MD, Rohde C et al. Endoscopicassisted linea alba reconstruction - New technique for treatment of symptomatic umbilical, trocar, and/or epigastric hernias with concomitant rectus abdominis diastasis. EurSurg. 2017. doi:10.1007/s10353-017-0473-1.

6. Lorenz R, Stechemesser B, Reinpold W et al. What are the needs for education in hernia surgery for the future? Eur Surg. 2017. doi:10.1007/s10353-017-0469-x.

7. Kimura M, Ishiguro H, Tanaka T, Mizoguchi K. A method for shaping a smooth gastric tube. Eur Surg. 2016. doi:10.1007/ s10353-016-0454-9.

8. Shirabe K, Tomoyuki A, Kajiyama K, Harimoto N. Prediction of 30-day mortality after emergency surgery for colorectal perforation: validation of the Portsmouth and colorectal physiologic and operative severity scoring systems for the enumeration of mortality and morbidity (P-POSSUM and Cr-POSSUM). Eur Surg. 2017; D-16. doi:10.1007/s10353016-0460-y.

9. Bonatti H. Laparoscopic appendectomy using only two $5 \mathrm{~mm}$ trocars. Eur Surg. 2017. doi:10.1007/s10353-0170465-1. 